\title{
A Study on Work Design and Country Values
}

\author{
*Ahsan Qamar, Saqib Muneer, Ahmad Jusoh, Halimah Idris \\ Faculty of Management and Human Resource Development, Universiti Teknologi Malaysia, Johor Malaysia \\ *ahsan_qkhan@yahoo.com
}

\begin{abstract}
The performance of an organization is dependent on the work design or in other words, the job design. It includes the elements of work included in the job as well as the work environment. With the creation of multinational companies operating in different countries, the cultural element has been added to the organization entity. The question has been whether work design of an MNC, which was originated in the country of origin of the MNC, can also be exported to other countries resulting in the same efficiency of work. This study through literature review looks into major work designs developed in various countries and regions of the world to answer the above given question i.e. whether culture is the moderating factor between job design and the performance.
\end{abstract}

\section{Keywords: Country Value, Work Design, National Culture, Organization}

\section{Introduction}

The motivation of an employee to do his/her job in the best possible way using his full potential is dependent on the perception of the employee about the significance and worthiness of the job itself. What kinds of jobs would an employee find more significant for himself or herself, depend on the cultural background of the particular employee? The cultural background, I am referring to here is the national culture of the country or area, the individual belong. Imagine there are two groups of people who are attending a program on international management training. One of these groups is the Chinese and the other group is the Americans. Suppose that each of the groups is given an assignment to do. The Chinese would most probably make a team and try to work out the assignment as teamwork, whereas the Americans would try to accomplish the assignment on an individual basis with minimum of communication between them. What does this indicate? Which is that the national cultures of people or individuals get the mindset about what kinds of jobs is more appreciative and which are not. The short description and the scenario given demonstrate the national culture has its influence on the design of jobs. People often mould their jobs to boost its significance according their own pattern of thinking (Wrzesniewski \& Dutton, 2001). However, the way persons shape their job is influenced by the culture of the geographical region where they belong. The cultures set the pattern in the minds of people, and these patterns have influence over the people's thinking's or in other words we can call it mindsets. On the basis of these mindsets people decide whether a certain work design is more significant and valuable or not. Design of Job, which include the arrangement order and composition of an individual's work related roles and responsibilities (Parker \& Ohly, 2008) depicts an individual's work environment. The work environment has a direct influence on the perception of a person whether a certain kind of job situation would facilitate or inhibit the prospect of success, well-being and self esteem (Erez, 2008).

The significance of this study is that it offers guidance to the multinational companies (MNCs) which plan to start their operations in other host countries (outside their country of origin) with entirely different national cultures. For those MNCs, their own management systems, values, ethics and work structures can-not be fully imposed in other cultures, and ultimately it may end up in losing some of its efficiency and effectiveness. Thus MNCs before expanding their operations overseas should research about the national cultural differences as well as other culture related characteristics. This would make sure that their future operations would be smooth in that country, without any surprises and setbacks. The scientific approach as developed by Taylor in the perspective of job design and work structure was good in terms of attaining high efficiency and productivity, but it lacked to provide the motivation to employees, which come from the employee's perception about the job being providing them self-esteem and well-being. The motivation is the force which is critical in keeping the employees to stay on the job and be highly productive. The self-esteem and well-being are the universal needs (Gelfand, Erez, \& Aycan, 2007). The crucial question that comes in mind is: What kind of work structure or design is the best for the creation of the perceptions of self-esteem and well-being? The answer to this question is different for different cultures. National and organizational cultures encompass the job designs. National cultures 
influence the organizational cultures therefore the individual who are working in the organizations are mentally programmed by the culture at the national level, which becomes the criteria to assess whether a certain work design would be able to provide the prospect of attaining the self-esteem and well-being (Erez \& Earley, 1993). Therefore various job designs were developed in various countries. Basically there are three prominent job design models which came out of three dissimilar cultures i.e. the Japan, Europe and United States. All the three models have the same aim of boosting the employee's self-esteem and well-being.

\section{Fig 1: National culture affects the job design through organizational culture}

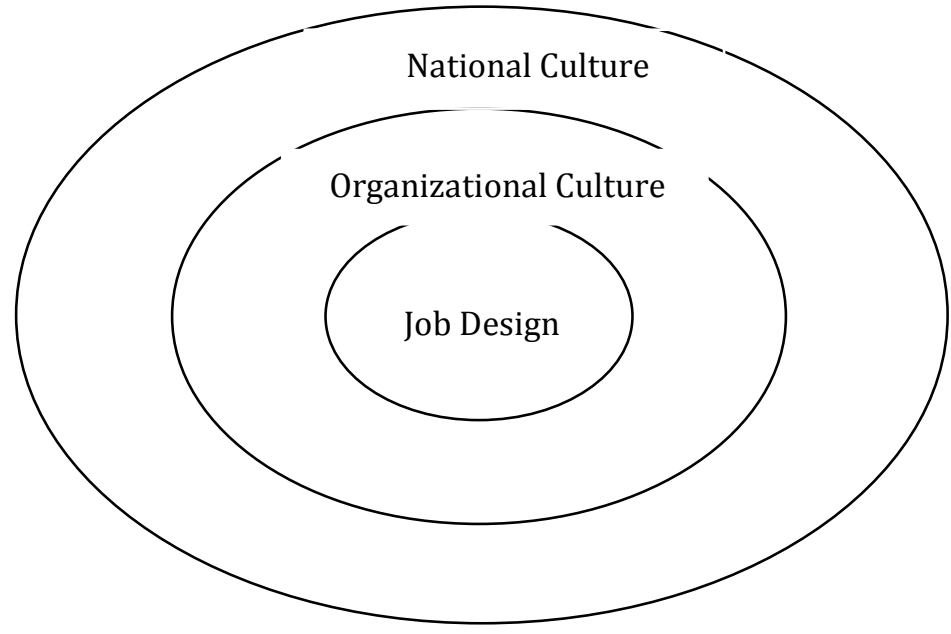

\section{Job design Model Developed in Japan}

QC circle concept had its emergence in Japan in 1960's and it spread throughout its manufacturing and production. The QC circle concept is that a small group, comprising of first-line workers who work independently to constantly control and enhance the quality of their products, network and services. Every QC circle seeks to develop member's potential and abilities by offering them the prospect to improve their self-esteem and make the place of work more enjoyable, important and satisfying. Customer satisfaction is thought to get enhanced by these activities and they also have a contribution towards the society. The QC circles comprise of somewhat homogeneous groups of workers. Their purpose is to create ideas for quality enhancement, to pinpoint problems and determine solutions. The QC circle approach was originally developed by W. Edward Deming, who himself was American but his approach was not originally accepted in America, but Japan was the one which applied the idea into practice. The reason being that Japan's culture fulfils the cultural requirements of QC circles but the American and European values are different from the requirements of QC circles. What are the elements of the Japan's culture which suited the concept of QC circles while it did not suit the American or European culture? There are basically two elements of the Japanese culture which matches the cultural requirements of QC circles and those are collectivism and power distance. Japan has a high rating on both aspects. Collectivism refers to group oriented culture where teamwork is focussed and is preferred mode of work, where individualistic approaches are discouraged. Power distance refers to classes in an organization or a society, where people in a society or an organization accept the unequal distribution of power and resources (House et al., 2004). QC circle require both collectivism and high power distance. The QC circle approach was not successful in America because the American culture values low collectivism as well as low power distance. These are contrary to the requirements of the QC circles. The same is true with the Europeans, their culture although supports collectivism but they value low power distance or in other words they value participative management, which is contrary to the requirement of the QC circle. Therefore the concept of QC circle is also was not that popular in Europe.

Job Design suited to the culture of Northern Europe: When the Europeans started to work towards improving their work through better job design, they explored in two dimensions i.e. to enhance the technical efficiency and self-esteem of the organizations, they were of the view that organization is made up of the association between the human system and the technological system (Trist, 1981). They did not agree with the Taylor's view of standardization and efficiency increase. They introduced this model of socio-technical job design which enhances the combination of both technical and social aspects of job 
design, which also considers the cultural ideals. This model's focus is not the individual employees but is executed at the group level and considers such aspects as autonomy, responsibility and the feedback at the group level and their effect on performance as well as how the task identity, skill variety and importance enhance the meaningfulness (Cherns, 1976; Emery \& Thorsrud, 1976). Although Europe and America are both western cultures but they have a difference in national culture. Particularly Europe if considered at societal level, scores high on collectivism which indicates that the societal institutions and organizations support and reward on the collective basis (House et al., 2004).

Job design model as developed by the United States: The work design developed in the United States is called the Job Enrichment model. The purpose of this model is to enhance the worker's critical mental state so that they should be able to achieve motivation from within, leading to job satisfaction and hence the higher productivity Hackman and Oldham's (1980). The features of job such as task identity, skill variety and the importance of task have a positive relationship to the feelings of meaningfulness and worthiness; the feelings of responsibility originate from work autonomy and feedback has positive effect of self correction behaviour (Bandura, 1986). These mental states lead to optimistic work outputs of motivation, job contentment and performance results. Hackman and Oldham realized that there are person to person differences so that some persons have a greater need for motivation and self growth than others, therefore they proposed further that those persons who have greater urge for personal growth and development would have a greater requirement for the two. There are several meta-analytic investigations which have supported their model (Fried \& Ferris, 1987; Loher, Noe, Moeller, \& Fitzgerald, 1985; Spector, 1985). The question is that why the job enrichment model was proposed in America not anywhere else and other models came from other countries. The reason is that the national culture of America suits the above mentioned model.

The American scores on the national cultural dimensions of individualism and power distance are the crucial determinants of its development of the job enrichment model; they show a quite high level of individualism and comparatively very low power distance (Hofstede, 2001; House, Hanges, Javidan, Dorfman, \& Gupta, 2004). These are the values which sets the focus on independent person who has the urge towards seld-esteem and well-being much more than others (Brewer \& Chen, 2007; Markus \& Kitayama, 1991), who is distinctive and exceptional (Kim \& Markus, 1999), who chooses to work by himself instead of being a part of group or team (Erez \& Earley, 1993). The model of Job enrichment provides the prospect of experiencing the feeling of autonomy and individual responsibility. Relational characteristics are of no concern in this job enrichment model as it is purely for the individualistic nature. As mentioned above there are three job design models developed by three societies having three different cultures. The purpose of all the three models are to provide the enhanced purposefulness, self-esteem and well-being, yet those are quite different approaches suited to the particular cultural values of the society from which those were originated. Hence the models of job design were moulded according to the cultural values.

\section{Does the Relationship between Job-design and Work outcome is moderated by Culture}

Nowadays is the era of globalization where information, humans, material and money can flow anywhere in the world. This globalization has created many opportunities as well as threats for companies. One of the biggest advantages for companies is that some of these companies have moved across borders to have their presence in several different countries. These are called Multinational companies (MNC). With MNC's one question comes in mind and which is that whether an MNC along with exporting their manufacturing facilities can also export their job design from the country of origin to the any other country? Based on the literature review this study would look into, whether relationship between Jobdesign and Work outcome is moderated by culture? Two characteristics of job design would be considered i.e. autonomy and feedback. Empowerment and work autonomy are regarded as crucial motivational aspects in cultures which emphasize individuals. Autonomy in work gives freedom to choose and make self decisions at own will (Chua \& Iyengar, 2006; cf. Chirkov, Ryan, Kim \& Kaplan, 2003). Autonomy in work enhances a person's feelings of responsibility, importance and control. But the next question is whether work autonomy be the same good in collectivist cultures as it is in individualistic cultures? Prior studies indicate that the relationship between work autonomy and satisfaction is dependent on the national culture.

This could be proved through some literature on collectivistic and individualistic countries. Indian nation culture has the characteristics of being highly collectivistic and high power distance. The literature shows 
that in Indian culture, those employees who were empowered were comparatively less satisfied as compared to the ones who were ordered by their bosses. Whereas in America with low power distance and high autonomy and empowerment, employees are most satisfied when given autonomy and empowerment (Robert, Probst, Martocchio, Drasgow, \& Lawler, 2000). In a different research, empowerment was found to have a positive relationship by the Canadians as well as the North Americans, but the Chinese individuals were not found to be positively related to it (Eylon \& Au, 1999). The obvious reason being that the Chinese collectivist society which prefers teamwork over individualistic approaches, their mindset is that they should be told by their superiors to do, their work outcome suffers if they are given the empowerment at work. Northern Europeans, with their individualistic cultures also relate positively to work autonomy as their system of employment is based on skills and not on control (Dobbin \& Boychuk, 1999). Studies have also found the relationship between individualistic culture and the economic growth of the countries, as there is a high emphasis on self growth in the individualistic societies. Some of the latest researchers have found the evidence that the developed countries have higher urge for self growth than the developing countries with collectivist mindsets (Deci, Ryan, Gagne, Leone, Usunov, \& Kornazheva, 2001; Huang \& Van de Vliert, 2003; Roe, Zinovieva, Dienes, \& Ten Horn, 2000).

The other characteristic of culture to be considered here is the feedback. This factor gets an individual understand the results of his attitude and behaviour and have higher internal control. The individualistic societies have greater urge for feedback because this gets more control to individuals so that they can control their own behaviours from the results associated with them. The collectivist cultures are associated with teams and groups where individuals are not as important as are the groups, so they do not emphasize on an individual feedback. For example Japanese managers are never expected to give individual feedback (Masumoto, 2004). Giving individual feedback in collectivist cultures is like spoiling the team coordination by appreciating a single person out of the whole team. Also if the negative feedback for an individual is conveyed then it insults the individual in the group and also is the insult for the whole group. In the collectivist cultures face saving is essential (Earley, 1997). Therefore in Japanese managers do not provide explicit feedback on the face but give implicit feedback informally.

Feedback if it is positive has a positive effect which is accepted as the universal fact. This was also indicated in a cross-cultural comparative study of Netherlands and China (Van de Vliert, Shi, Sanders, Wang, \& Huang, 2004). Besides that the collectivist countries prefer to have the collective feedback rather than the individual based (Van de Vliert et al., 2004). Similarly it has been found that those countries with individual based cultures prefer to have the feedback e.g. USA and the countries with collectivist cultures do not prefer to have the feedback e.g. Hong Kong (Chen, Brockner, \& Katz, 1998; Morrison, Chen, \& Salgado, 2004). Therefore summarising the results regarding the national cultures it is found that whether feedback is required or not depends on the culture of the country, some countries would like it others not, it would basically depend on the culture. Culture refers to the values, attitudes and behaviours etc. shared by the people of a certain country, as we call it national culture. Do the people of all the regions in a country share the same culture? Or are there any differences in culture between different regions of the same country. It has been found by various studies that regions in a country could have varying cultures. This is agreed that well being in United States is represented by high level skills, objective, life satisfaction, work, family and health. Though various regions within United States have different emphasis (Plaut, Markus, \& Lachman, 2002).

\section{Conclusion}

The previous literature on job design is mostly focussed on its direct relationship with the performance or the performer to describe how this relationship could be made more psychologically meaningful to the worker. Present investigation introduces the concept of culture between the job design and the performance of the organization. This study proves this relationship by determining that the major job design theories were developed according to the specific mindsets of the people of the particular countries or regions, where they were originated. Then it explains the cultural standing of the people of those countries or regions, describing some similarities and differences, thus proving that those job design theories would work best in the specific culture where it was originated and would lose its efficiency and meaningfulness in other regions of the world. The overall conclusion of this research is that the national culture does moderate the relationship of Job-Design and performance. 


\section{References}

Bandura, A. (1986). Social foundations of thought and action: A social cognitive theory. Englewood Cliffs, NJ: Prentice-Hall.

Brewer, M. B. \& Chen, Y. (2007). Where (and who) are collectives in collectivism: Toward conceptual clarification of individualism and collectivism. Psychological Review, 114, 133-151.

Chen, Y. R., Brockner, J. \& Katz, T. (1998). Toward an explanation of cultural differences in in-group favoritism: The role of individual versus collective primacy. Journal of Personality and Social Psychology, 75, 1490-1502.

Cherns, A. (1976). The principles of sociotechnical design. Human Relations, 29, 783-792.

Chirkov, V., Ryan, R. M., Kim, Y. \& Kaplan, U. (2003). Differentiating autonomy from individualism and independence: A self-determination theory perspective on internalization of cultural orientations and wellbeing. Journal of Personality \& Social Psychology, 84, 97-109.

Chua, R. Y. J. \& Iyengar, S. S. (2006). Empowerment through choice? A critical analysis of the effects of choice in organizations. In B. Staw, \& R. M. Kramer (Eds.). Research in organizational behavior, 27, 41-79.

Deci, E. L., Ryan, R. M., Gagne', M., Leone, D. R., Usunov, J. \& Kornazheva, B. P. (2001). Need satisfaction, motivation, and well-being in the work organizations of a former Eastern bloc country: A crosscultural study of self-determination. Personality and Social Psychology Bulletin, 27, 930-942.

Dobbin, F. \& Boychuck, T. (1999). National employment systems and job autonomy: Why job autonomy is high in the Nordic countries and low in the United States, Canada and Australia? Organization Studies, 20, 257-291.

Earley, P. C. (1997). Face, harmony, and social structure: An analysis of organizational behaviour across cultures. New York: Oxford University Press.

Emery, F. E. \& Thorsrud, E. (1976). Democracy at work. Leiden: Martinus Nijhoff.

Erez, M. (2008). Social-cultural influences on work motivation. In R. Kanfer, G. Chen, \& R. D. Pritchard (Eds.), Work motivation: Past, present, and future (501-538). Mahwah, NJ: Lawrence Erlbaum.

Erez, M. \& Earley, P. C. (1993). Culture, self-identity, and work. New York: Oxford University Press.

Eylon, D. \& Au, K. Y. (1999). Exploring empowerment cross-cultural differences among the power distance dimension. International Journal of Intercultural Relations, 23, 373-385.

Fried, Y. \& Ferris, G. R. (1987). The validity of the Job Characteristics Model: A review and meta-analysis. Personnel Psychology, 40, 287-322.

Gelfand, M. J., Erez, M. \& Aycan, Z. (2007). Cross-cultural organizational behavior. Annual Review of Psychology, 58, 479-514.

Hackman, J. R. \& Oldham, G. R. (1980). Work redesign. Reading, MA: Addison-Wesley.

Hofstede, G. (2001). Culture's consequences: Comparing values, behaviors, institutions and organizations across nations. Thousand Oaks, CA: Sage.

House, R. J., Hanges, P. W., Javidan, M., Dorfman, P. \& Gupta, V. (2004). Culture, leadership, and organizations: The GLOBE study of 62 societies. Thousand Oaks, CA: Sage Publications.

Huang, X., \& Van de Vliert, E. (2003). Where intrinsic job satisfaction fails to work: National moderators of intrinsic motivation. Journal of Organizational Behavior, 24, 159-179.

Kim, H. S. \& Markus, H. R. (1999). Deviance or uniqueness, harmony or conformity? A cultural analysis. Journal of Personality and Social Psychology, 77, 785-800.

Loher, B. T., Noe, R. A., Moeller, N. L. \& Fitzgerald, M. P. (1985). A meta-analysis of the relation of job characteristics to job satisfaction. Journal of Applied Psychology, 70, 280-289.

Markus, H. R. \& Kitayama, S. (1991). Culture and self: Implications for cognition, emotion and motivation. Psychological Review, 98, 224-253.

Masumoto, T. (2004). Learning to 'do time' in Japan: A Study of U.S. interns in Japanese organizations. International Journal of Cross-Cultural Management, 4, 19-37.

Morrison, E. W., Chen, Y. R. \& Salgado, S. R. (2004). Cultural differences in newcomer feedback seeking: A comparison of the United States and Hong Kong. Applied Psychology: An International Review, 53, $1-22$.

Parker, S. K. \& Ohly, S. (2008). Designing motivating jobs. In R. Kanfer, G. Chen, \& R. Pritchard (Eds.), Work motivation: Past, present, and future (233-284). Mahwah, NJ: Erlbaum.

Plaut, V. C., Markus, H. R. \& Lachman, M. E. (2002). Place matters: Consensual features and regional variation in American well-being and self. Journal of Personality and Social Psychology, 83, 160184. 
Robert, C., Probst, T. M., Martocchio, J. J., Drasgow, F. \& Lawler, J. J. (2000). Empowerment and continuous improvement in the United States, Mexico, Poland, and India: Predicting fit on the basis of the dimension of power distance and individualism. Journal of Applied Psychology, 85, 643-658.

Roe, R. A., Zinovieva, I. L., Dienes, E. \& Ten-Horn, L. (2000). A comparison of work motivation in Bulgaria, Hungary, and the Netherlands: Test of a model. Applied Psychology: An International Review, 49, 658-687.

Spector, P. E. (1985). Higher-order need strength as a moderator of the job scope-employee outcome relationship: A meta-analysis. Journal of Occupational Psychology, 58, 119-127.

Trist, E. L. (1981). The sociotechnical perspective. In A. H. Van de Ven, \& W. F. Joyce (Eds.), Perspectives on organization design and behavior (19-75). New York: Wiley.

Van-de-Vliert, E., Shi, K., Sanders, K., Wang, Y. \& Huang, X. (2004). Chinese and Dutch interpretations of supervisory feedback. Journal of Cross-Cultural Psychology, 35, 417-435.

Wrzensniewski, A. \& Dutton, J. E. (2001). Crafting a job: Revisioning employees as active crafters of their work. Academy of Management Review, 26, 179-201. 